www.jmscr.igmpublication.org

Impact Factor (SJIF): 6.379

Index Copernicus Value: 79.54

ISSN (e)-2347-176x ISSN (p) 2455-0450

crossrefDOI: https://dx.doi.org/10.18535/jmscr/v6i12.190

Journal Of Medical Science And Clinical Research

IGM Publication

An Official Publication of IGM Publication

\title{
Ultrasound Guided Fine needle aspiration Cytology evaluation of Solitary Thyroid Nodule - One year study
}

\author{
Authors \\ Dr Meena Mittal ${ }^{1}$, Prof. Dr C. V. Kulkarni ${ }^{2}$, Dr Khushboo Likhar ${ }^{3 *}$ \\ ${ }^{1}$ Associate Professor, Department of Pathology, M.G.M. Medical College, Indore \\ ${ }^{2}$ Professor and Head, Department of Pathology, M.G.M. Medical College, Indore \\ ${ }^{3}$ Senior Resident, Department of Pathology, M.G.M. Medical College, Indore \\ *Corresponding Author \\ Dr Khushboo Likhar
}

Senior Resident, Department of Pathology, M.G.M. Medical College, Indore, MP, India

Email:drkhushboo12@gmail.com

\begin{abstract}
Background: Ultrasound guided Fine needle aspiration Cytology decrease is a useful technique with minimum invasion and complication.

Objectives: To evaluate of solitary thyroid nodule by Ultrasound guided Fine needle aspiration Cytology. Method: This prospective study done on 30 patients with solitary thyroid nodule presenting in department of pathology from January 2018 to December 2018 to evaluate of solitary thyroid nodule by Ultrasound guided Fine needle aspiration Cytology. All patients clinically examined, ultrasound thyroid and Ultrasound guided Fine needle aspiration Cytology.

Result: 30 patients were included in our study in ratio female to male (6:1). Ultrasound guided Fine needle aspiration Cytology result showed that colloid nodule with follicular epithelium in 15 cases, colloid nodular goiter in 5 cases, hashimoto thyroiditis in 02 case, adenomatous nodule in 01 case and metastatic lesion in 07 cases in which papillary carcinoma in 06 cases and undifferentiated carcinoma in 01 case.

Conclusion: Ultrasound guide FNA has a high accuracy in diagnosis of solitary thyroid nodule with cytological features of malignancy.

Keywords: Thyroid nodule, ultrasound guided FNAC, Thyroid malignancy.
\end{abstract}

\section{Introduction}

Solitary nodule is a isolated swelling in one lobe without any abnormality elsewhere. Thyroid nodule can be hyperplastic, colloid, cystic, inflammatory and neoplastic ${ }^{[1]}$. Ultrasound is superior than FNAC only as needle is visualised in the lesion even in non-palpable nodule

\section{Material and Method}

The present study was done on 30 patients with solitary thyroid nodule presenting in department of pathology, M. Y. Hospital, Indore from January 2018 to December 2018 to evaluate of solitary thyroid nodule by FNAC under ultrasound guidance. All patients clinically examined, ultrasound thyroid and Ultrasound guided Fine needle aspiration Cytology. 


\section{Result}

Findings of bone marrow examination

\begin{tabular}{|l|c|}
\hline Finding & Number of cases \\
\hline Colloid nodule & 15 \\
\hline Nodular colloid goitre & 5 \\
\hline Hashimoto thyroiditis & 2 \\
\hline Malignant lesion & 7 \\
\hline Adenomatous nodule & 1 \\
\hline Total & 30 \\
\hline
\end{tabular}

Ultrasound guided Fine needle aspiration Cytology result showed that colloid nodule with follicular epithelium in 15 cases, colloid nodular goiter in 5 cases, hashimoto thyroiditis in 02 case, adenomatous nodule in 01 case and metastatic lesion in 07 cases in which papillary carcinoma in 06 cases and undifferentiated carcinoma in 01 case.

\section{Discussion}

Ultrasound guided Fine needle aspiration Cytology has high diagnostic accuracy in patient whom finding at FNAC can't differentiate between follicular adenoma and carcinoma. Aim of our study is to evaluate FNAC under U/S guidance. Ultrasound guided Fine needle aspiration Cytology result showed that colloid nodule with follicular epithelium in 15 cases, colloid nodular goiter in 5 cases, hashimoto thyroiditis in 02 case, adenomatous nodule in 01 case and metastatic lesion in 07 cases in which papillary carcinoma in 06 cases and undifferentiated carcinoma in 01 case. Linda B et.al $^{[2]}$ also found that $67 \%$ were benign and $7 \%$ were malignant and suspicious carcinoma in $2 \%$, $17 \%$ follicular neoplasm, atypia was $1 \%$. Similar study was done by Zubair WB et al study showed benign $63 \%$ and malignant $10 \%^{[3]}$. In the study done by Miseikyte-Kaubriene, they concluded benign lesion in $59.8 \%$ and malignancy in $22.5 \%{ }^{[4]}$. All these results in these study correlate with our results.

In our study found nodule in female at age 25-60 Year and in male 25-65 year with female to male ratio 6:1.Similar results were found in the study done by Rabia $\mathrm{B}$ et $\mathrm{al}^{[5]}$ found age for male and female range from $10-70 \mathrm{y}$ with female to male ratio 4.6:1. Anatomically 55\% were in the right lob, $40 \%$ in the left lob and $5 \%$ in isthmus. Veith FJ et $\mathrm{al}^{[6]}$ studied that $52 \%$ in the right lobe, $39 \%$ in the left lobe and $9 \%$ in the isthmus.

Ultrasound is a useful method of assessing nodule if cystic or solid, High resolution U/S improved diagnostic accuracy of U/S, by Ultrasound we assessed the nodule size, calcification, margin and vascularity, lymph node involvement and we used it as a guide for fine needle aspiration biopsy ${ }^{[7,8]}$.

\section{Conclusion}

Ultrasound guided FNAC is essential and reliable tool in evaluation and management of patient with solitary thyroid nodule. It is a minimally invasive procedure for pre operative evaluation of thyroid nodules, has accuracy in diagnosis of thyroid nodules and essential tool in evaluation of incidental and no palpable thyroid nodules.

\section{Reference}

1. Salab GB. Pathogenesis of thyroid nodule: histological classification, Biomed Pharmacother.2001;55:35-39.

2. Linda Band Miva M. Diagnostic Accuracy of Surgery - Performed UltrasoundGuided Fine Needle Aspiration of Thyroid Nodules. Annals of surgical oncology Jan 2012;19:45-51.

3. Zubair W, Baloch MD, Diane, et al.U/S guided FNAC biopsy of thyroid: Role of side assessment and multiple cytological preparation. Philadelphia, Pennsylvania 2000.

4. Miseikyte-Kaubriene E. The frequency of malignant disease in cytological group of suspected cancer (U/S guided FNAC of non palpable thyroid nodules. Lithuanian; 2008.

5. Rabia B and Mulazim HB. Comparison of fine needle aspiration cytology and thyroid scan in solitary thyroid nodules. 2011.

6. Veith FJ, Brooks JR, Grispy WP, Selenkow HA. The nodule thyroid gland and cancer: A practical approach to the 
problem. N. Engl. J.Med. 1994;270:431435.

7. Gondek S, Solorzano C, Lew JI. Surgeon performed ultrasound can predict benignity in thyroid nodules. surgery. sept 2011;150(3):436 -41.

8. Hegde A, Gopinathan A, Abu bakar R, Ooi CC, Koh YY, Lo RH.A method in the madness in ultrasound evaluation of thyroid nodules, Singapore Med J. Nov 2012 ;53(11):766-72; quiz p.773. 